\title{
Systematic Review and Meta-Analysis of Antibiotic- Impregnated Shunt Catheters on Anti-Infective Effect of Hydrocephalus Shunt
}

\author{
Wen-xiu Zhou, ${ }^{1}$ Wen-bo Hou, ${ }^{1}$ Chao Zhou, ${ }^{1}$ Yu-xia Yin, ${ }^{1}$ Shou-tao Lu, ${ }^{1}$ Guang Liu, ${ }^{1}$ Yi Fang, ${ }^{1}$ Jian-wen Li, ${ }^{1}$ Yan Wang, \\ Ai-hua Liu, ${ }^{2-4}$ Hai-jun Zhang ${ }^{1,5,6}$ \\ National United Engineering Laboratory for Biomedical Material Modification,' Branden Industrial Park, Dezhou, China \\ Department of Interventional Neuroradiology, ${ }^{2}$ Beijing Tiantan Hospital, Capital Medical University, Beijing, China \\ Beijing Neurosurgical Institute, ${ }^{3}$ Capital Medical University, Beijing, China \\ China National Clinical Research Center for Neurological Diseases, ${ }^{4}$ Beijing, China \\ Department of Vascular \& Intervention, ${ }^{5}$ Tenth People's Hospital of Tongji University, Shanghai, China \\ Department of Health Science and Technology, Faculty of Medicine, Aalborg University, Alborg, Denmark
}

Objective : Shunt infection is a common complication while treating hydrocephalus. The antibiotic-impregnated shunt catheter (AISC) was designed to reduce shunt infection rate. A meta-analysis was conducted to study the effectiveness of AISCs in reduction of shunt infection in terms of age, follow-up time and high-risk patient population.

Methods : This study reviewed literature from three databases including PubMed, EMBASE, and Cochrane Library (from 2000 to March 2019). Clinical studies from controlled trials for shunt operation were included in this analysis. A subgroup analysis was performed based on the patient's age, follow-up time and high-risk population. The fixed effect in RevMan 5.3 software (Cochrane Collaboration) was used for this meta-analysis.

Results : This study included 19 controlled clinical trials including 10105 operations. The analysis demonstrated that AISC could reduce the infection rate in shunt surgery compared to standard shunt catheter (non-AISC) from $8.13 \%$ to $4.09 \%$ (odds ratio [OR], $0.48 ; 95 \%$ confidence interval $[\mathrm{Cl}], 0.40-0.58 ; p=0.01 ; \mathrm{I}^{2}=46 \%$ ). Subgroup analysis of different age groups showed that AISC had significant antimicrobial effects in all three groups (adult, infant, and adolescent). Follow-up time analysis showed that AISC was effective in preventing early shunt infections (within 6 months after implant). AISC is more effective in high-risk population (OR, 0.24; $\left.95 \% \mathrm{Cl}, 0.14-0.40 ; p=0.60 ; \mathrm{I}^{2}=0 \%\right)$ than in general patient population.

Conclusion : The results of meta-analysis indicated that AISC is an effective method for reducing shunt infection. We recommend that AISC should be considered for use in infants and high-risk groups. For adult patients, the choice for AISC could be determined based on the treatment cost.

Key Words : Antibiotic-impregnated shunt catheters · Cerebrospinal fluid · Hydrocephalus · Infections.

- Received : October 31, 2019 •Revised : December 31, 2019 •Accepted : February 4, 2020

- Address for reprints : Hai-jun Zhang

Department of Vascular \& Intervention, Tenth People's Hospital of Tongji University, 301 Yanchang Middle Road, Shanghai 200072, China

Tel : +86-18653401666, Fax : +86-05345677386, E-mail : zhanghaijun@tongji.edu.cn, ORCID : https://orcid.org/0000-0002-3686-6346

This is an Open Access article distributed under the terms of the Creative Commons Attribution Non-Commercial License (http://creativecommons.org/licenses/by-nc/4.0) which permits unrestricted non-commercial use, distribution, and reproduction in any medium, provided the original work is properly cited. 


\section{INTRODUCTION}

Despite advances in catheter technology, shunt infection remains an issue of great concern for patients and surgeons. Patients who develop infection have a two-fold risk of mortality and a three-fold the time of shunt-related operations than those without infection. The reported prevalence of shunt infection varies from $1.5 \%$ to $69 \%^{7,24)}$. In a recent multicenter study of 41 pediatric hospitals in the United States, the rate of cerebrospinal fluid shunt infection ranged from $4.1 \%$ to $20.5 \%{ }^{1)}$. Interestingly, Choux et al. ${ }^{9)}$ indicated that a $0 \%$ infection rate is not an impossible goal. Although the incidence of shunt infection has decreased in developed countries in recent years $^{8,15)}$, infection remains a major cause of neurosurgical morbidity and mortality in developing countries.

Shunt infection is associated with lower IQ, poorer grades, increased seizure incidences, psychomotor retardation and decreased quality of life in children ${ }^{1939)}$. This also increases cost-related burden on the healthcare system and families. Coagulase-negative Staphylococcus is the main bacterial flora causing shunt infection because of its ability to form a biofilm on implanted materials. Staphylococcus aureus and Gramnegative bacilli are also common bacteria that cause shunt infection $^{38,40)}$

The control catheter in this study was made from silicone with no antimicrobial coating (non-antibiotic-impregnated shunt catheter, non-AISC). Recently, neurosurgeons have started using AISC in order to reduce the risk of shunt infection. The commonly used antimicrobial coating for shunt catheters contains $0.15 \%$ clindamycin and $0.054 \%$ rifampin $^{12)}$. The AISC system releases antibiotics to the catheter lumen and surrounding tissue at least 50 days after implantation ${ }^{5,34)}$. A recent non-systematic review suggested that AISC reduces the risk of ventriculo-peritoneal shunt infections ${ }^{17)}$. Konstantelias et al. ${ }^{28)}$ analyzed the effectiveness of antibiotic-impregnated coatings, silver-ion coatings and hydrogel coatings against infection. Thomas et al. ${ }^{48)}$ analyzed the effectiveness of AISCs in neonatal and adult patients. In conclusion, despite reports of effectiveness of these catheters, the published data for infection is not consistent. The meta-analysis of AISC infection with respect to follow-up time and high-risk patient population has not been systematically studied previously. Therefore, we report a comprehensive analysis of AISC effectiveness in this study.

\section{MATERIALS AND METHODS}

All randomized controlled trials were ethically approved. Based on the inclusion and exclusion criteria in this study, any research that conforms to the following criteria was included in the high-risk subgroup. 1) A priori as prematurity $(<37$ weeks gestational age), 2) shunts placed immediately postmeningitis, 3) conversion of external ventricular drains to shunt, 4) children with previous external ventricular drainage, and 5) frequent nosocomial infections. Shunting refers to ventriculoperitoneal, ventriculoatrial, ventriculopleural, lumboperitoneal, cystoperitoneal and subdural shunting. The antibiotics mainly used refer to $0.054 \%$ rifampicin and $0.15 \%$ clindamycin. The meta-analysis was performed and reported in accordance with Meta-analysis of Observational Studies in Epidemiology guidelines ${ }^{47)}$, the Preferred Reporting Items for Systematic Reviews and Meta-analyses statement ${ }^{31)}$, and the guidelines of Cochrane Collaboration.

\section{Search methods}

PubMed (from 2000 to March 2019), EMBASE (from 2000 to March 2019), and the Cochrane Library (from 2000 to March 2019) were reviewed independently by two authors (W.X.Z. and Y.F.). PubMed was searched using the following terms - 'ventriculo-peritoneal shunt' or 'cerebrospinal fluid

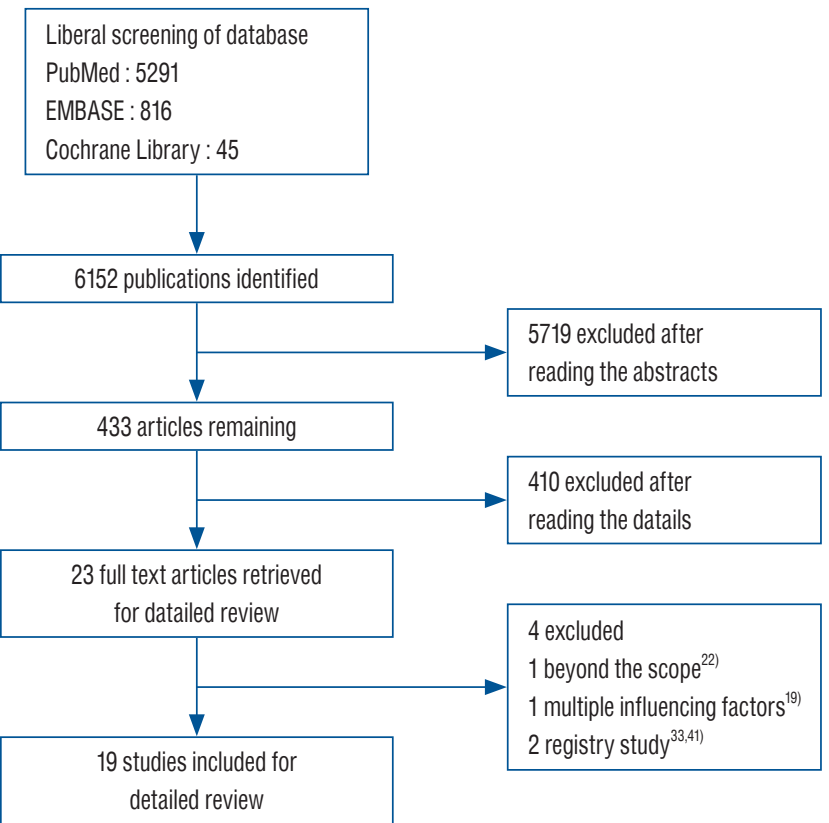

Fig. 1. Selection of studies based on inclusion criteria. 


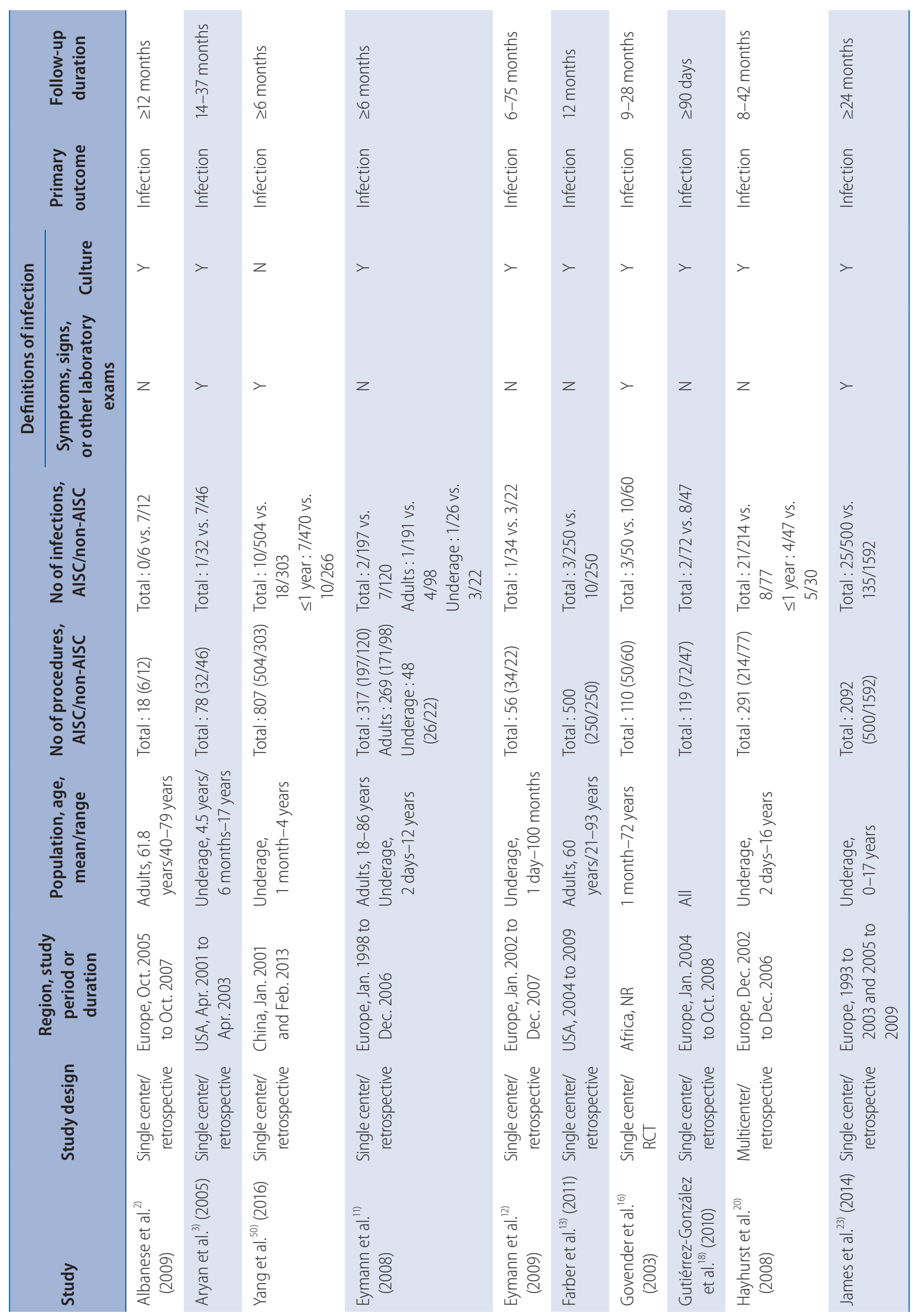




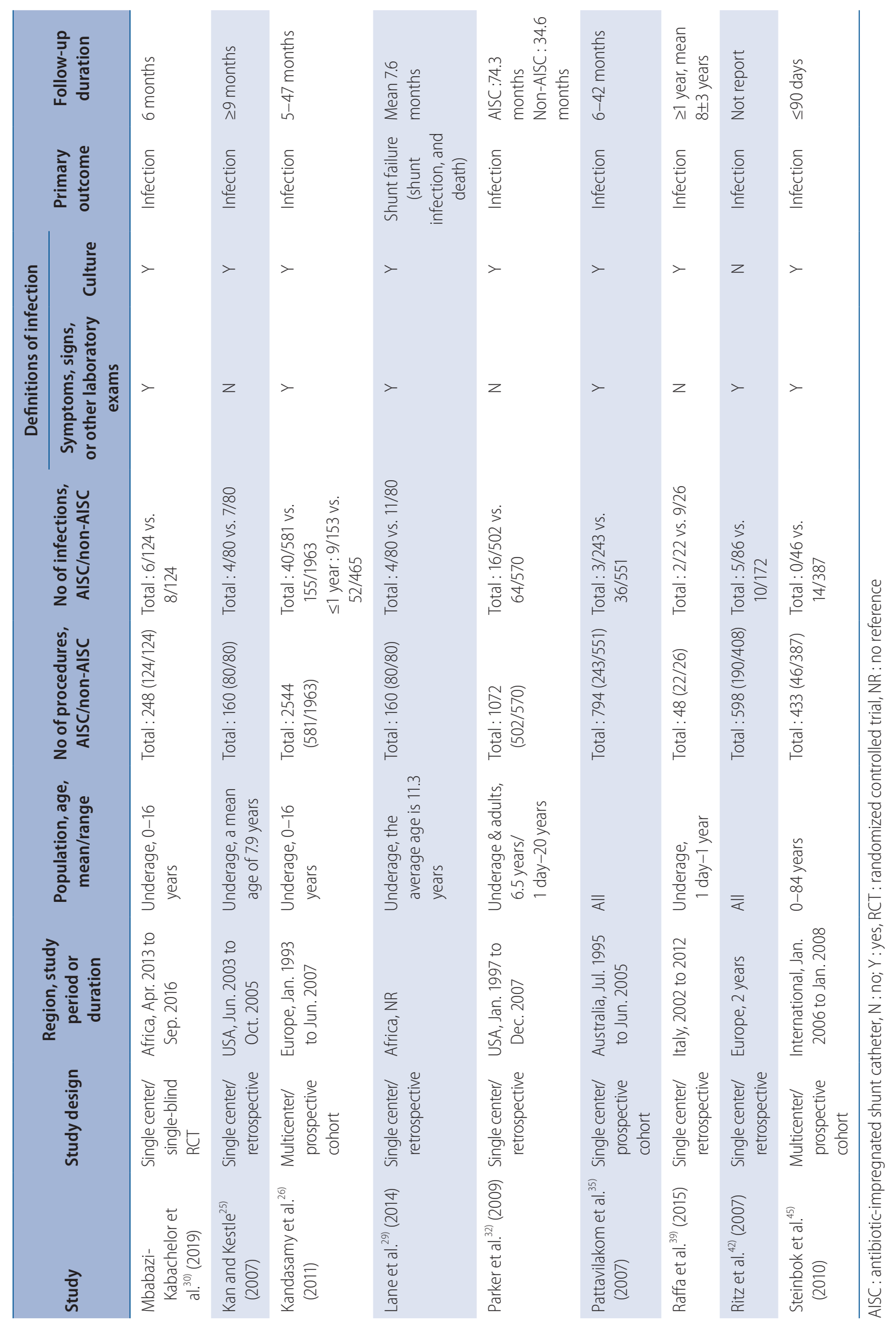


shunts' and 'infection'. EMBASE and Cochrane Library were searched using the following terms-'cerebrospinal fluid shunting and infection'.

\section{Study selection}

The study had to meet the following inclusion criteria, 1) retrospective or prospective randomized controlled trials of AISC versus non-AISC in antimicrobial effects of hydrocephalus shunt, 2) language used is English, and was excluded if, 1) less than 10 cases, 2) no control group, 3) repetitive published study.

\section{Data extraction}

The extracted data included study design, geographic area, follow-up time, population characteristics and outcomes (infection, mortality). Information obtained from the studies was recorded in standard data collection form by author (W.X.Z.), and two other authors (Y.F. and Y.W.), who independently examined these articles. Differences of opinion were resolved through discussion.

\section{Quality assessment}

The quality of randomized and nonrandomized studies was independently determined using the Cochrane Handbook ${ }^{21,46)}$ by authors (W.X.Z. and Y.F.). Differences of opinion were resolved through discussions and consultation with two other authors (Y.W. and J.W.L.).

\section{Data synthesis and statistical analysis}

The RevMan 5.3 software of the Cochrane Collaboration was used for data analysis, using fixed effects model. The odds ratio (OR) and 95\% confidence intervals (CIs) were calculated
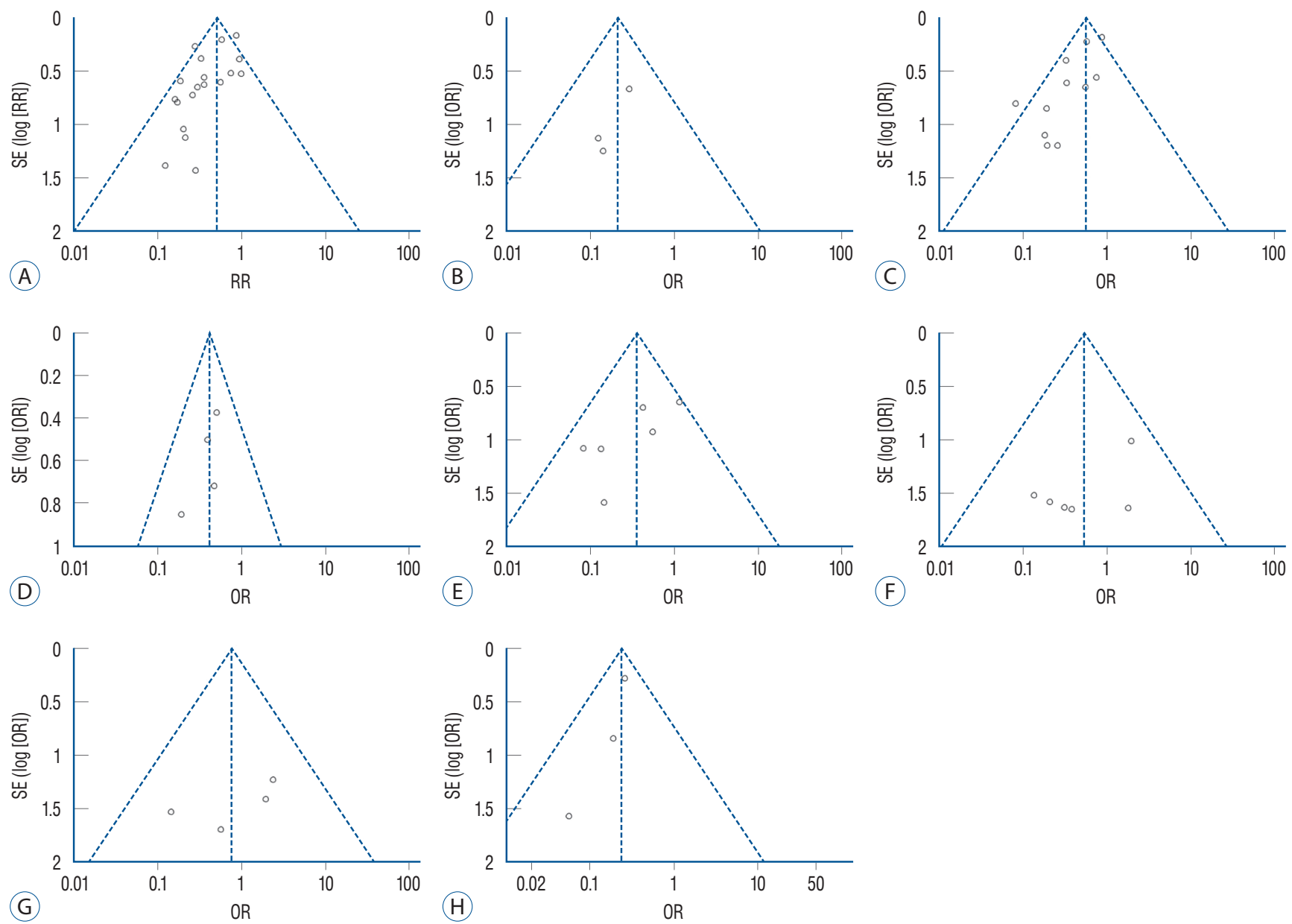

Fig. 2. Funnel plot to assess publication bias. A : A total of 19 studies, $B$ : adult group, $C$ : underage group, $D$ : infant group, E: 0-3 months group, F : 4-6 months group, $\mathrm{G}:>6$ months group, $\mathrm{H}$ : high-risk group. $\mathrm{SE}$ : standard error, $\mathrm{RR}$ : risk ratio, $\mathrm{OR}$ : odds ratio. 
for all outcomes. Heterogeneity across studies was assessed based on a standard chi-squared test with significance being set at $p<0.05$ or $\mathrm{I}^{2}>50 \%$. The extent of publication bias was estimated through visual inspection of funnel plot asymmetry.

\section{RESULTS}

\section{Description of studies}

It was initially determined to include 23 articles $^{2,3,11-13,16,18-20,22,23,25,26,29,30,32,33,35,39,41,42,45,50)}$, and finally confirmed to 19 articles $^{2,3,11-13,16,18,20,23,25,26,29,30,32,35,39,42,45,50)}$, four of which were excluded (Fig. 1) 19,22,33,41) . Details of the 19 studies included are in Table 1. The quality of the literatures were assessed in the Supplementary Tables 1 and 2.

The 19 studies included two randomized controlled trials, and there was certain heterogeneity in the findings ( $p=0.02$; $\mathrm{I}^{2}=44 \%$ ). Publication bias was detected (Fig. 2), which may be due to the tendency of researchers to publish superior results. However, we have not attempted to assess in detail since it was difficult to determine study quality in this area. No heterogeneity was found in the subgroup analysis.

\section{Research data}

A total of 19 studies were included in this meta-analysis. Data analysis showed that AISC had obvious advantages in terms of antimicrobial properties (OR, 0.48; 95\% CI, 0.400.58 ; $p<0.05 ; \mathrm{I}^{2}=46 \%$; Fig. 3 ), however, the data was heterogeneous.

\section{Age-based subgroup}

This study divided patients into three groups based on patient age (Fig. 4), i.e., adult group ( $\geq 18$ years), underage group $(<18$ years) and infant group ( $\leq 1$ year). Eleven studies of underage patients showed significantly better results with AISC (OR, 0.57; 95\% CI, 0.45-0.72; $p=0.05 ; \mathrm{I}^{2}=45 \%$ ), and the analysis was considerably significant $(p<0.01)$. Overall, four of the 11 studies were investigated in both the underage and the infant group. This analysis showed that the use of AISC in infant group (OR, 0.42; 95\% CI, $0.25-0.70 ; p=0.77 ; \mathrm{I}^{2}=0 \%$; $p<0.01$ ) was better than that in the underage group. There were only three studies in the adult group, and the results clearly showed that the use of AISCs in adult patients was significantly better (OR, 0.21; 95\% CI, 0.08-0.59; $p=0.76 ; \mathrm{I}^{2}=0 \% ; p<0.01$ ) than that of the entire patient population. Results indicated that the antimicrobial effects of using AISC in adult group is superior

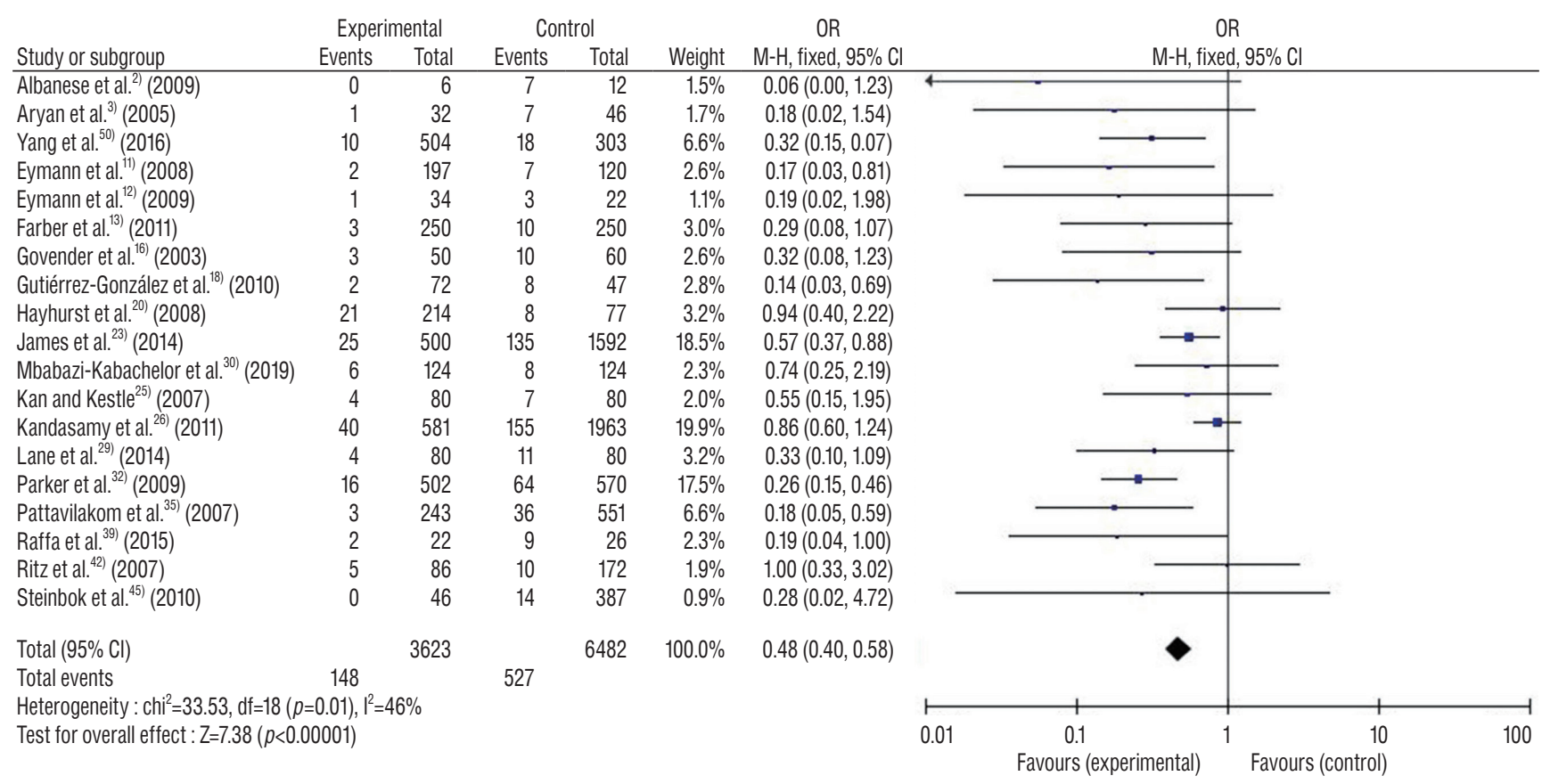

Fig. 3. Comprehensive analysis of anti-infection effect of AISC. OR : odds ratio, $\mathrm{M}-\mathrm{H}$ : mantel-haenszel, $\mathrm{Cl}$ : confidence interval, AISC : antibioticimpregnated shunt catheter. 
to that in underage group, and the antimicrobial effect of using AISC in infant group was better than that in the underage group.

\section{Follow-up schedule}

The incidence of infection during different follow-up period was also analyzed (Fig. 5). We divided the follow-up time into three stages : 0-3 months, 4-6 months, and longer than 6 months. The infection was defined as early infection (0-6 months) and late infection (longer than 6 months) according to Sciubba et al. ${ }^{44)}$. Our results showed that AISC has good antimicrobial effect (OR, 0.36; 95\% CI, 0.19-0.73; $p=0.25$;
$\mathrm{I}^{2}=25 \%$; $\left.p<0.01\right)$ in the $0-3$ months follow-up period, the antimicrobial effects decreased with increase in follow-up time. We found that the antimicrobial effect was still strong at 3-6 months (OR, 0.55; 95\% CI, 0.20-1.52; $p=0.62 ; \mathrm{I}^{2}=0 \% ; p=0.25$ ). The antimicrobial effect of AISC was basically non-existent (OR, 0.80; 95\% CI, 0.23-2.77; $p=0.48 ; \mathrm{I}^{2}=0 \% ; p=0.75$ ) at the end of 6 months after implantation. We did not observe any late shunt infection increase in AISC after 6 months of implantation (in the case of AISC group, 0-3 months infection rate : $4.27 \%$, 3-6 months infection rate : $1.22 \%$, longer than 6 months : $1.83 \%$ ). This was consistent with other studies having a follow-up period longer than 6 months ${ }^{2,16,39,42)}$.

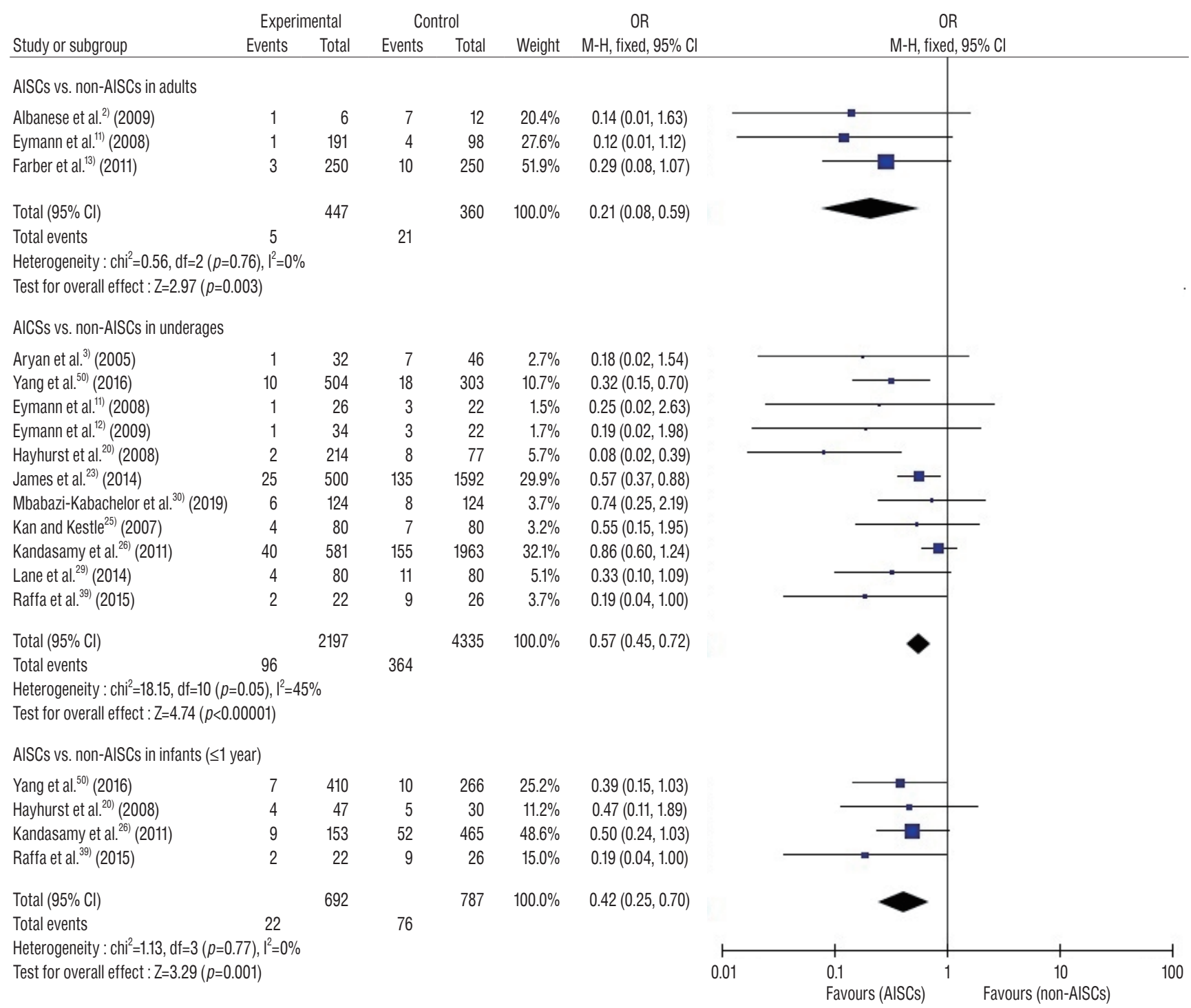

Fig. 4. Age-based subgroup analysis of the anti-infective effect of AISC. OR : odds ratio, $\mathrm{M}-\mathrm{H}$ : mantel-haenszel, $\mathrm{Cl}$ : confidence interval, AISC : antibioticimpregnated shunt catheter. 


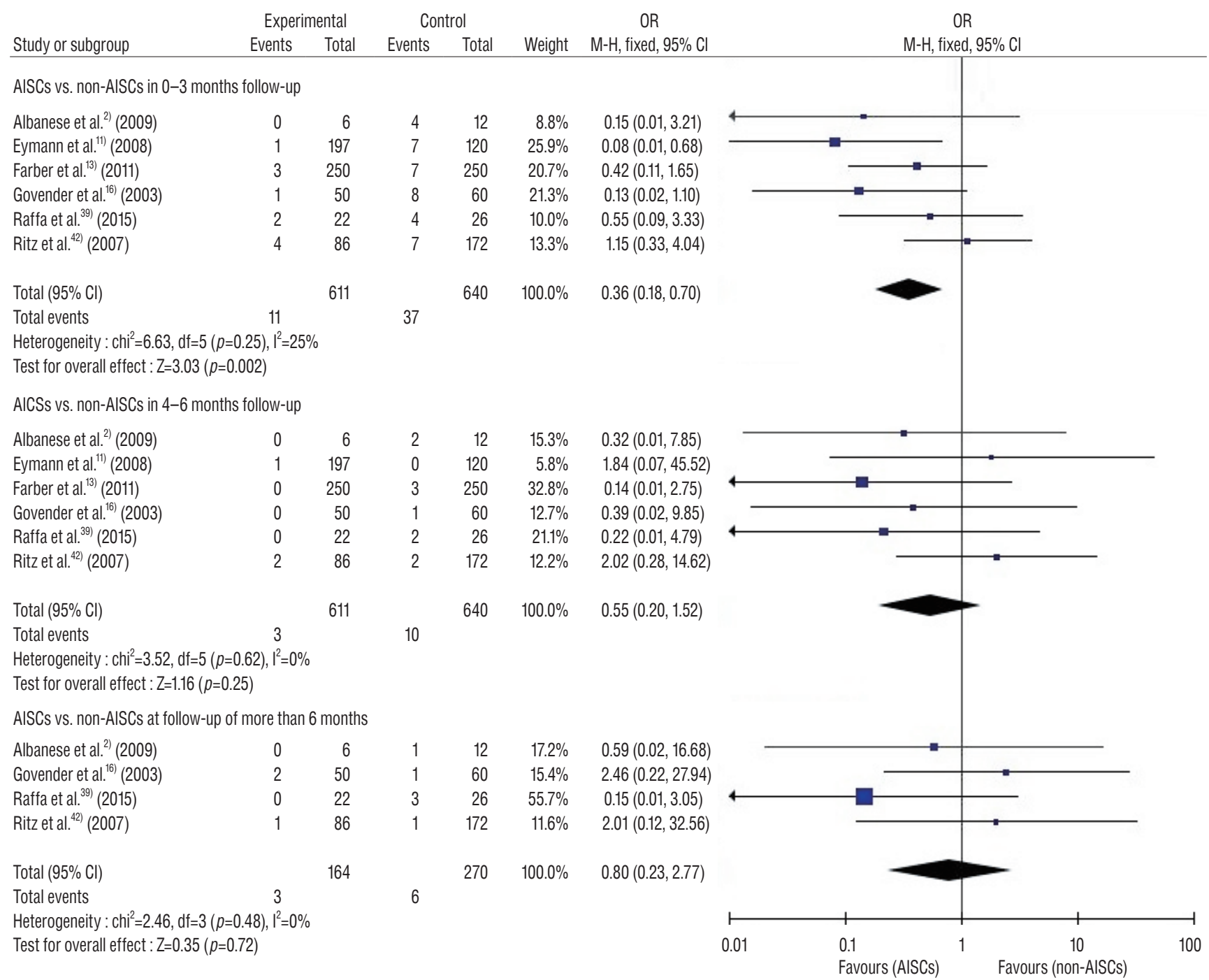

Fig. 5. Anti-infective effect of AISC in subgroups with different follow-up time. OR : odds ratio, $\mathrm{M}-\mathrm{H}$ : mantel-haenszel, $\mathrm{Cl}$ : confidence interval, AISC : antibiotic-impregnated shunt catheter.

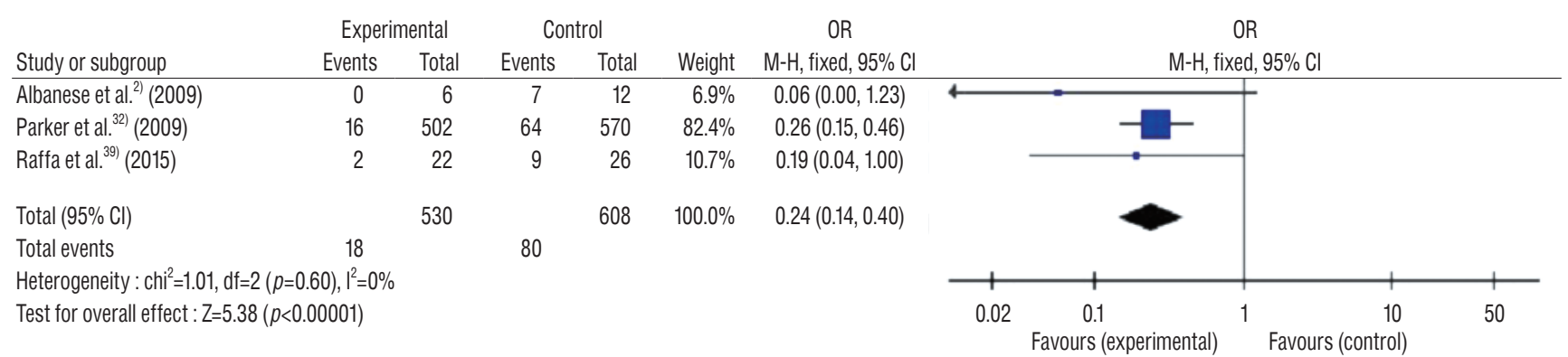

Fig. 6. Analysis of anti-infection effect of AISCs in high-risk subgroup. OR : odds ratio, $\mathrm{M}-\mathrm{H}$ : mantel-haenszel, $\mathrm{Cl}$ : confidence interval, AISC : antibioticimpregnated shunt catheter. 


\section{High-risk patients}

The antimicrobial effectiveness of AISC in high-risk patients was analyzed (Fig. 6). The results of three studies indicated that the anti-infective effect of AISC in high-risk population (OR, 0.24; 95\% CI, 0.14-0.40; $p=0.60 ; \mathrm{I}^{2}=0 \% ; p<0.01$ ) was higher than that of the entire patient population group.

\section{DISCUSSION}

This meta-analysis analyzed the effectiveness of AISC in preventing shunt infection compared with that of non-AISC. In sensitivity analysis, heterogeneity was found to be caused by large samples.

A total of 19 studies were divided into three groups according to patient age. Our results showed that the antimicrobial effect of AISC was related to patient age. The most prominent antimicrobial effect was found in the adult group, and it was superior in the infant group compared to the underage group. This was consistent with the results of Konstantelias et al. ${ }^{28)}$. In the Bayston study, the rate of infection for hydrocephalus shunting was higher in non-AISC subgroup amongst infants. The closer the age of the patient to the adult population, the lower the infection rate ${ }^{4)}$. This is also consistent with our statistical results. This could be attributed to issues in the child's immune system development, fragility of the skin and high density of skin bacteria ${ }^{37)}$. Farber showed that AISC usage could reduce infection-related cost per patient ${ }^{14)}$. However, in adults from lower socio-economic strata, non-AISC is an alternative, especially where there are fewer high-risk factors. Since the results analyzed showed that adult patients have low infection rate $(5.8 \%)$ compared to those of other two groups (infant $9.66 \%$ and underage $8.40 \%$ ), it is recommended to consider non-AISC implant to reduce the cost of treatment, unless high risk factors prevail.

The infection rate in 19 studies (divided into three groups) was analyzed based on the follow-up period. It can be seen that infection mainly occurred in the early stages of implantation and the late infection rate decreased with increase in follow-up time $e^{10,27,36)}$. The study indicated consistency with previous reported results. Early infection may be caused by perioperative bacterial colonization on the shunt and acute immune reaction to implanted device, although the cause of late infection is clinically unclear ${ }^{6,36,43,49)}$. The statistical results of non-AISC dem- onstrated that the infection rate was higher in the early stage of shunting (post implant 0-3 months), proving that antimicrobial effects of AISC was most required during this stage. Once the follow-up period exceeded 6 months, AISC tended to lose its antimicrobial function due to drug dilution, however, it did not lead to an increase in the incidence or toxicity of late period shunt infection. This research further indicated that the antimicrobial effects of AISC within 3-6 months of implantation got weaker compared to the first 0-3 months, and it totally lost antimicrobial function after 6 months.

Three studies were included in the analysis of anti-infective properties of AISCs in high-risk populations. AISC was obviously effective in the high-risk population. In high-risk patients, the use of AISC reduced the incidence of shunt infections from $13.16 \%$ for non-AISCs to $3.40 \%$, which was consistent with the infection rate of $4.08 \%$ in the general population using AISC; the infection rate using non-AISC for the general population is $8.13 \%$. There are several factors in highrisk groups, like coexisting symptoms, invasive surgeries, prolonged bed rest, inactivity, repeated exposure to bacterial environment in the hospital and other factors that can cause infection. Under these high-risk factors, the infection rate with the use of antimicrobial catheters had the same effect as with the use of antibiotics in the general population, which proved that antimicrobial catheters were most effective in high-risk populations. We recommend using antimicrobial catheters in high-risk populations.

\section{Limitation}

Most of the studies included in this meta-analysis are singlecenter, retrospective data with certain limitations. The present meta-analysis showed that AISC could reduce the incidence of complications associated with infection. However, large multicenter RCTS are still needed to further confirm this result.

\section{CONCLUSION}

Subgroup analysis of demonstrated patient age is an important factor associated with shunt infection, especially in infant population, that has a higher predilection for infections. The follow-up time analysis indicated that the antimicrobial effects should remain effective for at least 6 months in order to reduce the infection rate in the $3-6$ months post-implantation 
period, which could be achieved by improving drug efficacy and coating technology. AISC is recommended for high-risk patients who are susceptible to infection. Non-AISCs may be considered for adult patients without high-risk infection factors, to reduce the cost of treatment. The revision of implanted shunt and hydrocephalus etiology are also significant factors accounting for patient infection, which are not included in this analysis and deserve further investigation in the future in terms of efficiency and safety.

\section{CONFLICTS OF INTEREST}

No potential conflict of interest relevant to this article was reported.

\section{INFORMED CONSENT}

This type of study does not require informed consent.

\section{AUTHOR CONTRIBUTIONS}

\author{
Conceptualization : HJZ, WBH, AHL \\ Data curation : WXZ, YF, YW, JWL \\ Formal analysis : CZ, YXY, STL, GL \\ Funding acquisition : HJZ \\ Methodology : WBH, WXZ \\ Project administration : HJZ, WBH \\ Visualization: WXZ, WBH \\ Writing - original draft : WXZ, WBH \\ Writing - review \& editing : HJZ, WBH, WXZ
}

\section{ORCID}

Wen-xiu Zhou
Wen-bo Hou
Chao Zhou
Yu-xia Yin
Shou-tao Lu
Guang Liu
Yi Fang
https://orcid.org/0000-0002-6769-329X https://orcid.org/0000-0002-0176-8869 https://orcid.org/0000-0003-3615-1794 https://orcid.org/0000-0002-3658-2634 https://orcid.org/0000-0002-4145-4573 https://orcid.org/0000-0001-6675-9085 https://orcid.org/0000-0002-2172-3799
Jian-wen Li https://orcid.org/0000-0001-5959-9861 Yan Wang https://orcid.org/0000-0001-7922-0732

Ai-hua Liu https://orcid.org/0000-0002-9324-413X

Hai-jun Zhang https://orcid.org/0000-0002-3686-6346

\section{- Supplementary materials}

The online-only data supplement is available with this article at https://doi.org/10.3340/jkns.2019.0219.

\section{References}

1. Adams DJ, Rajnik $M$ : Microbiology and treatment of cerebrospinal fluid shunt infections in children. Curr Infect Dis Rep $16:$ 427, 2014

2. Albanese A, De Bonis P, Sabatino G, Capone G, Marchese E, Vignati A, et al. : Antibiotic-impregnated ventriculo-peritoneal shunts in patients at high risk of infection. Acta Neurochir (Wien) 151 : 1259-1263, 2009

3. Aryan HE, Meltzer HS, Park MS, Bennett RL, Jandial R, Levy ML : Initial experience with antibiotic-impregnated silicone catheters for shunting of cerebrospinal fluid in children. Childs Nerv Syst 21 : 56-61, 2005

4. Bayston R : Hydrocephalus shunt infections. J Antimicrob Chemother 34 Suppl A : 75-84, 1994

5. Bayston R, Grove N, Siegel J, Lawellin D, Barsham S: Prevention of hydrocephalus shunt catheter colonisation in vitro by impregnation with antimicrobials. J Neurol Neurosurg Psychiatry 52 : 605-609, 1989

6. Bayston R, Lari J : A study of the sources of infection in colonised shunts. Dev Med Child Neurol 16(6 Suppl 32) : 16-22, 1974

7. Braga MH, Carvalho GT, Brandão RA, Lima FB, Costa BS : Early shunt complications in 46 children with hydrocephalus. Arq Neuropsiquiatr 67(2A) : 273-277, 2009

8. Choux M, Genitori L, Lang D, Lena $G$ : Shunt implantation: reducing the incidence of shunt infection. J Neurosurg $77:$ 875-880, 1992

9. Choux M, Lena G, Genitori L, Empime E, Riss JM : Shunt ImplantationToward Zero Infection : Childs Nervous System. New York : Springer, 1988, p181

10. Enger PØ, Svendsen F, Wester K : CSF shunt infections in children: experiences from a population-based study. Acta Neurochir (Wien) 145 : 243-248; discussion 248, 2003

11. Eymann R, Chehab S, Strowitzki M, Steudel WI, Kiefer M : Clinical and economic consequences of antibiotic-impregnated cerebrospinal fluid shunt catheters. J Neurosurg Pediatr 1 : 444-450, 2008

12. Eymann $\mathrm{R}$, Steudel $\mathrm{WI}$, Kiefer $\mathrm{M}$ : Infection rate with application of an antibiotic-impregnated catheter for shunt implantation in children - a retrospective analysis. Klin Padiatr 221 : 69-73, 2009

13. Farber SH, Parker SL, Adogwa O, McGirt MJ, Rigamonti D : Effect of antibiotic-impregnated shunts on infection rate in adult hydrocephalus: a single institution's experience. Neurosurgery 69 : 625-629; discussion 629, 2011 
14. Farber SH, Parker SL, Adogwa O, Rigamonti D, McGirt MJ : Cost analysis of antibiotic-impregnated catheters in the treatment of hydrocephalus in adult patients. World Neurosurg 74 : 528-531, 2010

15. George R, Leibrock L, Epstein $M$ : Long-term analysis of cerebrospinal fluid shunt infections. A 25-year experience. J Neurosurg 51 : 804811, 1979

16. Govender ST, Nathoo N, van Dellen JR : Evaluation of an antibioticimpregnated shunt system for the treatment of hydrocephalus. J Neurosurg $99: 831-839,2003$

17. Gutiérrez-González R, Boto GR : Do antibiotic-impregnated catheters prevent infection in CSF diversion procedures? Review of the literature. J Infect $61:$ 9-20, 2010

18. Gutiérrez-González R, Boto GR, Fernández-Pérez C, del Prado N : Protective effect of rifampicin and clindamycin-impregnated devices against Staphylococcus spp. infection after cerebrospinal fluid diversion procedures. BMC Neurol $10: 93,2010$

19. Harrop JS, Sharan AD, Ratliff J, Prasad S, Jabbour P, Evans JJ, et al. : Impact of a standardized protocol and antibiotic-impregnated catheters on ventriculostomy infection rates in cerebrovascular patients. Neurosurgery 67 : 187-191; discussion 191, 2010

20. Hayhurst C, Cooke R, Williams D, Kandasamy J, O'Brien DF, Mallucci CL : The impact of antibiotic-impregnated catheters on shunt infection in children and neonates. Childs Nerv Syst 24 : 557-562, 2008

21. Higgins JP, Wells GA : Cochrane handbook for systematic reviews of interventions. Hoboken : John Wiley \& Sons, 2011

22. Jaeger $W$, Lee $S$, Vineet $D$, Keil A, Agarwal N, Rao S : Ventriculoperitoneal shunts in neonates: a retrospective study of outcomes with antibiotic-impregnated catheters and a modified peri-operative antibiotic protocol. Br J Neurosurg 31 : 672-676, 2017

23. James G, Hartley JC, Morgan RD, Ternier J : Effect of introduction of antibiotic-impregnated shunt catheters on cerebrospinal fluid shunt infection in children: a large single-center retrospective study. J Neurosurg Pediatr 13 : 101-106, 2014

24. James HE, Bradley JS : Aggressive management of shunt infection: combined intravenous and intraventricular antibiotic therapy for twelve or less days. Pediatr Neurosurg 44 : 104-111, 2008

25. Kan P, Kestle $\mathrm{J}$ : Lack of efficacy of antibiotic-impregnated shunt systems in preventing shunt infections in children. Childs Nerv Syst 23 : 773777, 2007

26. Kandasamy J, Dwan K, Hartley JC, Jenkinson MD, Hayhurst C, Gatscher $S$, et al. : Antibiotic-impregnated ventriculoperitoneal shunts--a multicentre British paediatric neurosurgery group (BPNG) study using historical controls. Childs Nerv Syst 27 : 575-581, 2011

27. Kestle J, Drake J, Milner R, Sainte-Rose C, Cinalli G, Boop F, et al. : Longterm follow-up data from the Shunt Design Trial. Pediatr Neurosurg $33: 230-236,2000$

28. Konstantelias AA, Vardakas KZ, Polyzos KA, Tansarli GS, Falagas ME : Antimicrobial-impregnated and-coated shunt catheters for prevention of infections in patients with hydrocephalus: a systematic review and meta-analysis. J Neurosurg 122 : 1096-1112, 2015

29. Lane JD, Mugamba J, Ssenyonga P, Warf BC : Effectiveness of the
Bactiseal Universal Shunt for reducing shunt infection in a sub-Saharan African context: a retrospective cohort study in 160 Ugandan children. J Neurosurg Pediatr 13 : 140-144, 2014

30. Mbabazi-Kabachelor E, Shah M, Vaughan KA, Mugamba J, Ssenyonga $P$, Onen J, et al. : Infection risk for Bactiseal Universal Shunts versus Chhabra shunts in Ugandan infants: a randomized controlled trial. J Neurosurg Pediatr 23 : 397-406, 2019

31. Moher D, Liberati A, Tetzlaff J, Altman DG : Preferred reporting items for systematic reviews and meta-analyses: the PRISMA statement. Ann Intern Med 151 : 264-269, 2009

32. Parker SL, Attenello FJ, Sciubba DM, Garces-Ambrossi GL, Ahn E, Weingart J, et al. : Comparison of shunt infection incidence in high-risk subgroups receiving antibiotic-impregnated versus standard shunts. Childs Nerv Syst 25 : 77-83; discussion 85, 2009

33. Parker SL, McGirt MJ, Murphy JA, Megerian JT, Stout M, Engelhart L : Comparative effectiveness of antibiotic-impregnated shunt catheters in the treatment of adult and pediatric hydrocephalus: analysis of 12,589 consecutive cases from 287 US hospital systems. J Neurosurg 122 : 443-448, 2015

34. Pattavilakom A, Kotasnas D, Korman TM, Xenos C, Danks A : Duration of in vivo antimicrobial activity of antibiotic-impregnated cerebrospinal fluid catheters. Neurosurgery 58 : 930-935; discussion 930-935, 2006

35. Pattavilakom A, Xenos C, Bradfield O, Danks RA : Reduction in shunt infection using antibiotic impregnated CSF shunt catheters: an Australian prospective study. J Clin Neurosci 14 : 526-531, 2007

36. Piatt JH Jr : Cerebrospinal fluid shunt failure: late is different from early. Pediatr Neurosurg 23 : 133-139, 1995

37. Pople IK, Bayston R, Hayward RD : Infection of cerebrospinal fluid shunts in infants: a study of etiological factors. J Neurosurg $77: 29$ 36, 1992

38. Prusseit J, Simon M, von der Brelie C, Heep A, Molitor E, Volz S, et al. : Epidemiology, prevention and management of ventriculoperitoneal shunt infections in children. Pediatr Neurosurg 45 : 325-336, 2009

39. Raffa G, Marseglia L, Gitto E, Germanò A : Antibiotic-impregnated catheters reduce ventriculoperitoneal shunt infection rate in high-risk newborns and infants. Childs Nerv Syst 31 : 1129-1138, 2015

40. Rehman AU, Rehman TU, Bashir HH, Gupta V : A simple method to reduce infection of ventriculoperitoneal shunts. J Neurosurg-Pediatr 5 : 569-572, 2010

41. Richards HK, Seeley HM, Pickard JD : Efficacy of antibiotic-impregnated shunt catheters in reducing shunt infection: data from the United Kingdom Shunt Registry. J Neurosurg Pediatr 4 : 389-393, 2009

42. Ritz R, Roser F, Morgalla M, Dietz K, Tatagiba M, Will BE : Do antibioticimpregnated shunts in hydrocephalus therapy reduce the risk of infection? An observational study in 258 patients. BMC Infect Dis $7: 38$, 2007

43. Sciubba DM, McGirt MJ, Woodworth GF, Carson B, Jallo GI : Prolonged exposure to antibiotic-impregnated shunt catheters does not increase incidence of late shunt infections. Childs Nerv Syst 23 : 867-871, 2007

44. Sciubba DM, Stuart RM, McGirt MJ, Woodworth GF, Samdani A, Carson 
B, et al. : Effect of antibiotic-impregnated shunt catheters in decreasing the incidence of shunt infection in the treatment of hydrocephalus. J Neurosurg 103(2 Suppl) : 131-136, 2005

45. Steinbok P, Milner R, Agrawal D, Farace E, Leung GK, Ng I, et al. : A multicenter multinational registry for assessing ventriculoperitoneal shunt infections for hydrocephalus. Neurosurgery 67 : 1303-1310, 2010

46. Sterne JA, Hernán MA, Reeves BC, Savović J, Berkman ND, Viswanathan $M$, et al. : ROBINS-I: a tool for assessing risk of bias in non-randomised studies of interventions. BMJ 355 : i4919, 2016

47. Stroup DF, Berlin JA, Morton SC, Olkin I, Williamson GD, Rennie D, et al. : Meta-analysis of observational studies in epidemiology: a proposal for reporting. Meta-analysis of observational studies in epidemiology
(MOOSE) group. JAMA 283 : 2008-2012, 2000

48. Thomas R, Lee S, Patole S, Rao S : Antibiotic-impregnated catheters for the prevention of CSF shunt infections: a systematic review and metaanalysis. Br J Neurosurg 26 : 175-184, 2012

49. Vinchon $M$, Lemaitre MP, Vallée $L$, Dhellemmes $P$ : Late shunt infection: incidence, pathogenesis, and therapeutic implications. Neuropediatrics 33 : 169-173, 2002

50. Yang B, Song Y, Gao P, Bao N : Prevention of infection by antibioticimpregnated shunts after pediatric hydrocephalus treatment: a single center, retrospective study in China. Clin Neurol Neurosurg 151 : 9295,2016 